\section{Tumor necrosis factor-alpha inhibitor combined with methotrexate for ankylosing spondylitis: a systematic review and meta-analysis}

\author{
Shaopeng Lin, Mingyu He, Junmin Chen \\ Department of Hematology and \\ Rheumatology, the First Affiliated \\ Hospital of Fujian Medical University, \\ Fuzhou, China
}

\section{Abstract}

To evaluate the benefits and harms of combination of tumor necrosis factor-alpha (TNF- $\alpha$ ) inhibitor and methotrexate (MTX) compared with TNF- $\alpha$ inhibitor monotherapy in the treatment of ankylosing spondylitis (AS). Randomized controlled trials were identified from Medline, Embase, Cinahl, Central and Clinical Trials Registry Platform, as well as from the reference sections of retrieved articles. The risk of bias was evaluated in all included trials. Data were extracted by two reviewers independently using a specially designed extraction form. The Cochrane Collaboration's Review Manager 5.2 software was used for data analysis. The search retrieved 852 titles, of which 3 original trials were included, involving 187 participants. The overall risk of bias is low in all three trials. Only one study was placebo controlled, and all of them examined small samples. The analysis showed no significant advantage of the MTX combination versus monotherapy. Two trials assessed Assessment of Ankylosing Spondylitis (ASAS) 40 and the pooled risk ratio (RR) was 1.37 and $95 \%$ confidence interval 0.84 to 2.23 . The RR for ASAS20 was 1.16 (0.88 to 1.52 ). Likewise, there were no significant difference between two groups in partial remission, Bath Ankylosing Spondylitis Disease Activity Index, Bath Ankylosing Spondylitis Functional Index, Magnetic resonance imaging activity score and other secondary outcomes. Withdrawals for side effects and for any reason were similar in two groups, RR were 1.89 ( 0.71 to 5.02) and 1.11 (0.67 to 1.84$)$, respectively. The evidence available did not support any benefit of adding MTX to TNF- $\alpha$ inhibitor for the treatment of AS.

\section{Introduction}

Ankylosing spondylitis (AS) is a chronic inflammatory disease of unknown cause and belongs to a group of diseases known as spondyloarthropathies (SpA), which includes reactive arthritis, arthritis/spondylitis in inflammatory bowel disease, psoriatic arthritis/spondylitis and undifferentiated SpA. The disease starts usually in the third decade of life, and manifests more often in men than in women (ratio 2:1). ${ }^{1}$ Disease progression may result in loss of mobility and function, and therefore patients can experience a heavy disease burden, with pain and stiffness, loss of physical function, and severe impairment in quality of life.,3

Nonsteroidal anti-inflammatory drugs (NSAIDs) are the cornerstone of pharmaceutical treatment of AS. Methotrexate (MTX), one of conventional disease-modifying antirheumatic drugs (DMARDs), has been extensively used, although this practice is not supported by ASAS/EULAR recommendations. ${ }^{4}$ Tumor necrosis factor-alpha (TNF- $\alpha$ ) inhibitors have proven highly effective in improving mobility, function, C-reactive protein and quality of life for AS patients. ${ }^{5-12}$

Combination of TNF- $\alpha$ inhibitor and MTX has been extensively studied in rheumatoid arthritis (RA). ${ }^{13,14}$ Evidence showed combination therapy brought more benefits than TNF$\alpha$ inhibitor monotherapy. ${ }^{15,16}$ For AS, however, whether it is the case is unclear. The aim of this review is to examine the benefits and harms of TNF- $\alpha$ inhibitors in combination with MTX compared with TNF- $\alpha$ inhibitors alone in the treatment of AS.

We planned the review protocol as followed.

\section{Materials and Methods}

\section{Types of studies}

We included randomized and quasi-randomised trials.

\section{Types of participants}

Participants were patients with AS fulfilling one of the following and other criteria: 1961 Rome, 1966 New York, modified 1984 New York, Amor or ESSG (European Spondyloarthropathy Study Group) criteria. ${ }^{17}$ Studies with spondyloarthropathies/spondyloarthritis patients as participants were included if there were available data assessing the outcomes specific to patients with AS. Patients were male or female, with or without the involvement of peripheral joints.

\section{Types of interventions}

The intervention was TNF- $\alpha$ inhibitor (including infliximab, etanercept, adalimum$\mathrm{ab}$, golimumab and certolizumab) combined with MTX (any dosage and any delivery route) for at least 12 weeks. The comparison was combination therapy versus TNF- $\alpha$ inhibitor alone or combination therapy versus TNF- $\alpha$ inhibitor plus placebo.
Correspondence: Junmin Chen, Department of Hematology and Rheumatology, The First Affiliated Hospital of Fujian Medical University, Chazhong Road 20, 350005 Fuzhou, Fujian Province, China.

Tel.: +86.591.87981678 - Fax: +86.591 .83318716$

E-mail: drjunminchen@hotmail.com

Key words: combination therapy, tumor necrosis factor-alpha inhibitor, methotrexate, ankylosing spondylitis, systematic review.

Acknowledgments: the authors would like to thank Mulleman, Li, Griffith, Breban and Ravaud for offering the extra information about their studies.

Contributions: the authors contributed equally.

Conflict of interests: the authors declare no potential conflict of interests.

Received for publication: 15 October 2013.

Revision received: 20 February 2014.

Accepted for publication: 24 March 2014.

This work is licensed under a Creative Commons Attribution NonCommercial 3.0 License (CC BYNC 3.0).

(C) Copyright S. Lin et al., 2014

Licensee PAGEPress, Italy

Rheumatology Reports 2014; 6:5127

doi:10.4081/rr.2014.5127

\section{Types of outcome measures}

Major outcomes are: i) assessment of Ankylosing Spondylitis (ASAS) response: ASAS40, ASAS20, ASAS 5/6, partial remission; ii) bath index: Bath ankylosing spondylitis function index (BASFI), Bath ankylosing spondylitis disease activity index (BASDAI), Bath ankylosing spondylitis metrology index (BASMI); iii) change in radiograph and magnetic resonance imaging (MRI); iv) withdrawals due to side effect; v) drop-out for any reason; vi) serious side effects.

Minor outcomes are: i) physical function; ii) pain; iii) spinal mobility and spinal stiffness; iv) peripheral joints/entheses (pain, swelling and tenderness); v) patient global assessment and physician global assessment; vi) fatigue; vii) level of acute phase reactants, including erythrocyte sedimentation rate (ESR) and Creactive protein (CRP).

\section{Search methods for identification of studies}

Relevant randomized and quasi-randomized trials in any language were sought using the following sources: MEDLINE (1946 to January 3, 2013), EMBASE (1974 to January 3, 2013), 
CINAHL (1937 to January 3, 2013), CENTRAL (Cochrane Central Register of Controlled Trials, December, 2012), Clinical Trials Registry Platform (January 3, 2013) and the reference sections of retrieved articles.

\section{Selection of studies}

Publications retrieved from Central, Medline, Embase, Cinahl and the Clinical Trials Registry Platform were imported in a reference management software (EndNote X5). After removing the duplicate results, unblinded trial reports were reviewed independently by SL and MH according to the selection criteria. Disagreements were resolved by consensus and by recourse to the third review author (JC) if necessary.

\section{Data extraction and management}

Data extracted from the included trials were recorded on a pre-structured data extraction and were entered independently into Review Manager 5.2 software by the same review authors. Only outcomes specified in the protocol were included in the review. Continuous data (e.g. visual analogue scales of pain, patient's global assessment) were entered as means and standard deviations (SD), and dichotomous outcomes (e.g. response, improvement) as number of events.

\section{Data analysis}

We analyzed only the available data for continuous data. For dichotomous data, we used intention-to-treat (ITT) analysis. Heterogeneity was explored by the chi-squared test (Chi ${ }^{2}$ test) with significance set at $\mathrm{P}$ value 0.10 . The quantity of heterogeneity was measured by $\mathrm{I}^{2}$ with $\mathrm{I}^{2} \geq 50 \%$ as substantial heterogeneity. We performed meta-analysis, using Review Manager 5.2 software. A random-effect model was used to combine the results where heterogeneity was significant. Otherwise, a fixed-effect model was used. Sub-group analysis by characteristics of participants (e.g. different AS classification criteria, male or female, with or without peripheral arthritis) and intervention (e.g. different dosage, different duration) were planned. Two sensitivity analyses were planned according to whether: i) the allocation to intervention or control groups was truly randomized or quasi-randomized, to explore the potential selection bias; ii) the outcome assessment was blinded, to explore the potential assessment bias associated with knowledge of the intervention.

\section{Assessment of risk of bias in included studies}

We assessed risk of bias in all included studies using The Cochrane Collaboration's tool for assessing risk of bias (Supplementary Files). ${ }^{18}$ There were six domains: random sequence generation, allocation concealment, blinding of outcome assessment, incomplete outcome data, selective reporting and other sources of bias such as baseline imbalance. We made a judgment about risk of bias according to the criteria described in the Cochrane Handbook. ${ }^{18}$ Risk of bias was categorized as Low risk, High risk or Unclear risk. The included trials were independently assessed by the review authors, using a data collection form. Funnel plot was planned to detect publication bias. However, this plan was given up when we found that only three trials were included.

\section{Results}

\section{Results of the search}

Our search retrieved 852 citations. After review of titles and abstracts and removal of duplicates across databases, ten records were identified for further evaluation. Seven records were excluded for different reasons (Figure 1). ${ }^{19-25}$ Therefore, only three studies were retained for our analysis. ${ }^{26-28}$ Figure 1 showed the study selection process.

\section{Included studies}

Three randomized controlled trials met the inclusion criteria. In Breban 2008 trial, ${ }^{26}$ all patients were scheduled to receive a loading regimen of infliximab (IFX) (5 mg/kg in 250 mL normal saline at week 4,6 , and 10). Thereafter, patients were randomized into two groups, continuous treatment group receiving IFX infusions regularly, and on-demand group receiving supplementary infusions only upon relapse. Patients in the on-demand group were further randomized to receive IFX alone or IFX plus MTX. MTX was given orally at a maximum dose of $12.5 \mathrm{mg}$ weekly. Only the data of ondemand IFX group patients were included in the present review. Li et al. ${ }^{27}$ compared IFX (5 $\mathrm{mg} / \mathrm{kg}$ in $250 \mathrm{~mL} 0.9 \% \mathrm{NaCl}$ at week 16,18 and 22) plus MTX (15 mg weekly, orally) with IFX plus placebo over 30 weeks. Patients in Mulleman 2011 trial were randomized to receive IFX alone (infusions of $5 \mathrm{mg} / \mathrm{kg}$ at week $0,2,6,12$ and 18) or IFX combined with MTX (10 mg/week, orally). ${ }^{28}$ These three trials included a total of 187 participants, 94 receiving IFX and MTX combination therapy and 93 IFX monotherapy. The sample size ranged from 26 to 123 . Over 20 outcomes were assessed. All the patients among the included participants fulfilled the modified New York criteria. Male patients accounted for about 79\%. Depending on the trial, the age and the duration of disease was reported as a mean or median value. The age ranged from 26.1 to 53.6 and the dis-

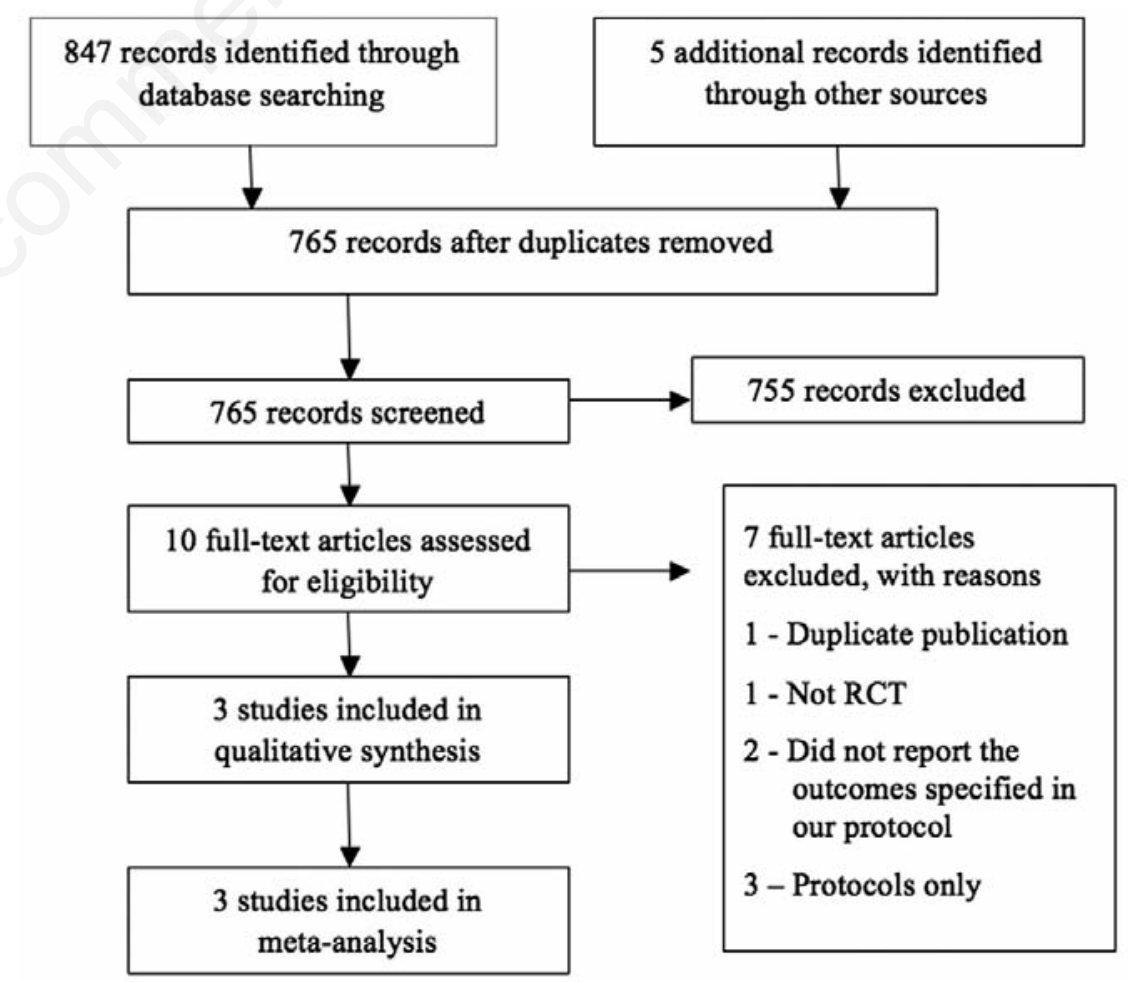

RCT, randomized clinical trial.

Figure 1. Flow chart of the trial selection process. 
ease duration of major participants ranged from 5.4 to 27.5 years. All the participants were patients with active disease but the definitions of active disease varied among the trials. Further details were available in the Table 1.

\section{Excluded studies}

Krzysiek reported circulating concentration of IFX in Breban 2008 trial, ${ }^{20,26}$ which has been included in the present review. Pérez-Guijo 2007 trial was excluded because this was not a randomized clinical trial (RCT). ${ }^{19}$ Ternant 2012 trial and Ducourau 2010 trial were two papers of a same study, ${ }^{21,22}$ assessing the influence of MTX on the variability of IFX pharmacokinetics and concentration-effect relationship in axial ankylosing spondylitis (AAS) patients. They were excluded because they did not report the outcomes specified in the present review. NCT1, ${ }^{23}$ NCT2 $2{ }^{24}$ and NCT3 ${ }^{24}$ are clinical trial records registering in www.clinicaltrials.gov.
These ongoing trials were not included because the results were not available.

\section{Risk of bias in included studies}

The risks of bias of included trials were summarized in Table 2.

\section{Allocation (selection bias)}

Random sequence generation and allocation concealment were judged as low risk of bias in all these three trials. In Breban 2008 trial, ${ }^{26}$ randomization was centralized by the coordinating center and communicated to other centers by fax. The methods of randomization were generated by a computer in both Li 2008 trial and Mulleman 2011 trial and kept by the school pharmacy and sealed opaque envelopes, respectively. ${ }^{27,28}$

Blinding (performance bias and detection bias)

Patients and researchers in Li 2008 trial were blinded and therefore blinding was judged as low risk of bias. ${ }^{27}$ Placebo was not used in Breban 2008 trial and Mulleman 2011 trial. ${ }^{26,28}$ The performance bias and detection bias were judged as high risk of bias in these two trials.

Incomplete outcome data (attrition bias)

In Breban 2008 trial, ${ }^{26} 28 \%$ participants did not complete the 1-year trial. However, the reasons for discontinuation were well balanced between treatment groups. There were 3 and 1 patients dropping out in Li 2008 trial and Mulleman 2011,27,28 respectively. ITT analysis was used for all outcomes in both Breban 2008 and Li 2008. ${ }^{26,27}$ Therefore, all three trials were scored as low risk of bias.

\section{Selective reporting (reporting bias)}

The protocols were available for all the trials and results of all pre-specified outcomes reported. Therefore, all three trials were judged as low risk of bias.

Table 1. Summary of included studies' characteristics.

\begin{tabular}{|c|c|c|c|c|c|c|c|c|c|}
\hline Author & $\begin{array}{l}\text { Sample sine } \\
(\mathrm{M} / \mathrm{F})\end{array}$ & $\begin{array}{l}\text { Intt } \\
\text { Age } \\
\text { (meant } \\
\text { range) }\end{array}$ & $\begin{array}{l}\text { Dention gro } \\
\text { Disease } \\
\text { duration } \\
\text { (meant } \\
\text { range) }\end{array}$ & $\begin{array}{l}\text { Treatment } \\
\text { protocol }\end{array}$ & $\begin{array}{l}\text { Age } \\
\text { (meant } \\
\text { range) }\end{array}$ & $\begin{array}{l}\text { ntrol group } \\
\text { Disease } \\
\text { duration } \\
\text { (meant } \\
\text { range) }\end{array}$ & $\begin{array}{l}\text { Treatment } \\
\text { protocol }\end{array}$ & Follow-up & $\begin{array}{l}\text { Main } \\
\text { outcomes }\end{array}$ \\
\hline Breban & $123(95 / 28)$ & $42.7 \pm 10.9$ & $16.4 \pm 11.1$ & $\begin{array}{l}\text { IFX: } 5 \mathrm{mg} / \mathrm{kg}, \mathrm{IV} . \text {., } \\
\text { weeks } 4,6 \text {, and } 10 . \\
\text { Thereafter the dose } \\
\text { was increased to } 7.5 \mathrm{mg} / \mathrm{kg} \text {, } \\
\text { if relapse occurred as early } \\
\text { as } 3 \text { weeks after an infusion. } \\
\text { MTX: } 2.5 \mathrm{mg} \text {, orally, weekly, } \\
\text { from week } 1 \text { to weeks } 4 \text {, } \\
\text { increased } 2.5 \mathrm{mg} \text { weekly, up } \\
\text { to a maximum dose of } 12.5 \mathrm{mg}\end{array}$ & $40 \pm 9.6$ & $13.8 \pm 7$ & $\begin{array}{l}\text { IFX: The same as } \\
\text { intervention group }\end{array}$ & 58 weeks & $\begin{array}{l}\text { ASAS response; } \\
\text { Partial remission; } \\
\text { BASDAI; BASFI; } \\
\text { Withdrawal for side effect; } \\
\text { Withdrawal for any reason }\end{array}$ \\
\hline $\mathrm{Li}$ & $38(32 / 6)$ & $37 \pm 10.9$ & $12.1 \pm 10.4$ & $\begin{array}{l}\text { IFX: } 5 \mathrm{mg} / \mathrm{kg}, \text { I.V., weeks } 16,18,22 \text {. } \\
\text { MTX: initially } 7.5 \mathrm{mg} \text { orally, weekly, } \\
\text { increased } 2.5 \mathrm{mg} \text { every } 2 \text { weeks } \\
\text { up to } 15 \mathrm{mg} \text { by week } 6\end{array}$ & $39.4 \pm 9.9$ & $11.1 \pm 6.7$ & $\begin{array}{l}\text { IFX: The same as } \\
\text { intervention group } \\
\text { Placebo: placebo } \\
\text { tablets were given } 6 \\
\text { in the sam } \\
\text { way as MTX }\end{array}$ & 30 weeks & $\begin{array}{l}\text { ASAS response; } \\
\text { Partial remission; } \\
\text { BASDAI; BASFI; } \\
\quad \text { MRI activity score; } \\
\text { Withdrawal for side effect; } \\
\text { Withdrawal for any reason }\end{array}$ \\
\hline Mullemar & $26(20 / 6)$ & $29-50$ & $1-19$ & $\begin{array}{l}\text { IFX: } 5 \mathrm{mg} / \mathrm{kg}, \mathrm{I} . \mathrm{V} . \text {, weeks } 0,2,6 \text {, } \\
\text { 12, } 18 \text { MTX: } 10 \text { mg, orally, weekly }\end{array}$ & $27-59$ & $0-28$ & $\begin{array}{l}\text { IFX: The same as } \\
\text { intervention group }\end{array}$ & 18 weeks & $\begin{array}{l}\text { ASAS response } \\
\text { BASDAI }\end{array}$ \\
\hline
\end{tabular}

IFX, infliximab; MTX, methotrexate; I.V., intravenously; ASAS, assessments in ankylosing spondylitis; BASDAI, Bath Ankylosing Spondylitis Disease Activity Index; BASFI, Bath Ankylosing Spondylitis Functional Index; MRI, Magnetic Resonance Imaging.

Table 2. Summary of the risk of bias assessment results of the included studies.

\begin{tabular}{|c|c|c|c|}
\hline Domain & Breban et $a l$. & Li et $a l$. & Mulleman et al. \\
\hline Was the allocation sequence adequately generated? & + & + & + \\
\hline Was allocation adequately concealed? & + & + & + \\
\hline Was knowledge of the allocated interventions adequately prevented during the study? & + & + & + \\
\hline Blinding of personnel & - & + & - \\
\hline Blinding of participants & - & + & - \\
\hline Blinding of outcome assessors & - & + & - \\
\hline Were incomplete outcome data adequately addressed? & + & + & + \\
\hline Are reports of the study free of suggestion of selective outcome reporting? & + & + & + \\
\hline Was the study apparently free of other problems that could put it at a risk of bias? & + & + & + \\
\hline
\end{tabular}


Other potential sources of bias

All the included trials appeared to be free of other sources of bias and therefore judged as low risk of bias.

\section{Effects of interventions}

\section{Major outcomes}

Two trials assessed ASAS40 and none of them found significant difference between IFX plus MTX combination therapy and IFX monotherapy. ${ }^{26,27}$ Risk ratios (RR) were 1.49 and 1.00 and $95 \%$ confidence interval (CI) were 0.86 to 2.59 and 0.35 to 2.90 , respectively. The pooled RR was 1.37 (95\% CI 0.84 to 2.23) and no significant heterogeneity was found between these two trials (Figure 2A). ASAS20 responses were available in all three included trials. No significant difference was found between the intervention groups in either the individual trial data or pooled data. Pooled RR was 1.16 and $95 \%$ CI 0.88 to 1.52 (Figure 2B).

Breban 2008 trial and Li 2008 trial assessed partial remission which was defined as a value of 2 or less on a $0-10$ scale in each of the 4 domains of the ASAS40.26,27 No significant difference was found between combination therapy and monotherapy. Pooled RR was 1.42 and 95\% CI 0.47 to 4.29 (Figure 2C).

Two trials assessed BASFI (0-10 scale) (Figure $3 \mathrm{~A}$ ) and all three included trials assessed BASDAI (0-10 scale) (Figure $3 \mathrm{~B}) .^{26-28}$ There was no significant difference between intervention groups in either individual or pooled result, whether end point data or change from baseline data were analyzed. No significant heterogeneity was found among these trials. Weighted mean difference (WMD) of endpoint value were $-0.04(-0.76$ to 0.67$)$ for BASFI and 0.29 ( -0.32 to 0.90$)$ for BASDAI, respectively.

The spine MRI activity score was assessed only in Li 2008 trial and an overall improvement of $36.4 \%$ was found in all the 31 available participants, but no significant difference was found between the intervention groups. WMD was -0.65 (-4.21 to 2.91). ${ }^{27}$

For safety outcomes, slightly higher rates of drop-out for side effect and any reason were found in combination therapy group than monotherapy group. Pooled RR were 1.89 ( 0.71 to 5.02 ) and 1.11 ( 0.67 to 1.84$)$, respectively. No statistically significant difference was found between intervention groups (Figure 4A,B). Eight serious events were reported in all three trials. Six were in Breban 2008 trial (1 sudden death attributed to likely myocardial infarction, 1 solid cancer and 3 serious infection in combination therapy group and 1 serious infection in monotherapy group) ${ }^{26}$ and 1 each in Li 2008 trial (mycetoma with Scedosporium apiospermum) ${ }^{27}$ and Mulleman 2011 trial (septicaemia in combination therapy group). ${ }^{28}$ We did not conduct a meta-analysis for this outcome, because Li 2008 trial did not specify which group the patient came from. ${ }^{27}$

\section{Minor outcomes}

Data of physical function, peripheral joints/entheses (pain, swelling and tenderness) and fatigue were not reported in the included trials.

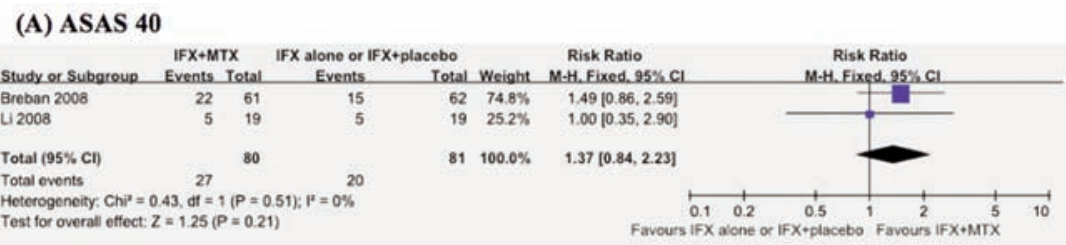

(B) ASAS 20

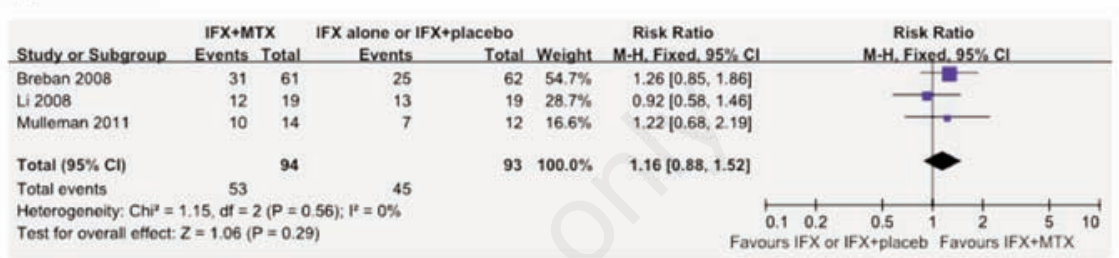

(C) Partial remission

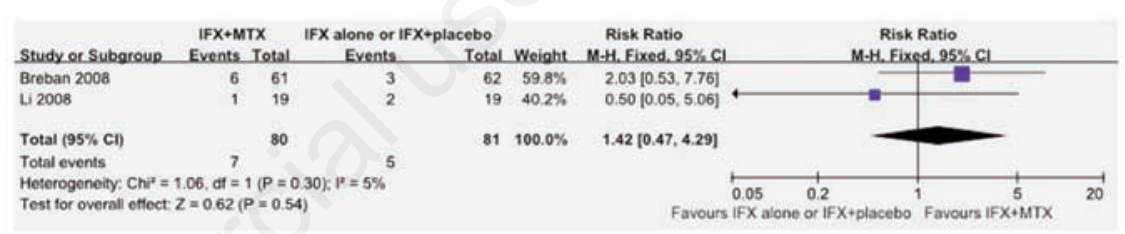

Figure 2. Forest plots of the ASAS response and partial remission of combination therapy versus monotherapy in ankylosing spondylitis. IFX, infliximab; MTX, methotrexate; ASAS, assessments in ankylosing spondylitis; CI, Confidence Interval; M-H, MantelHaenszel.

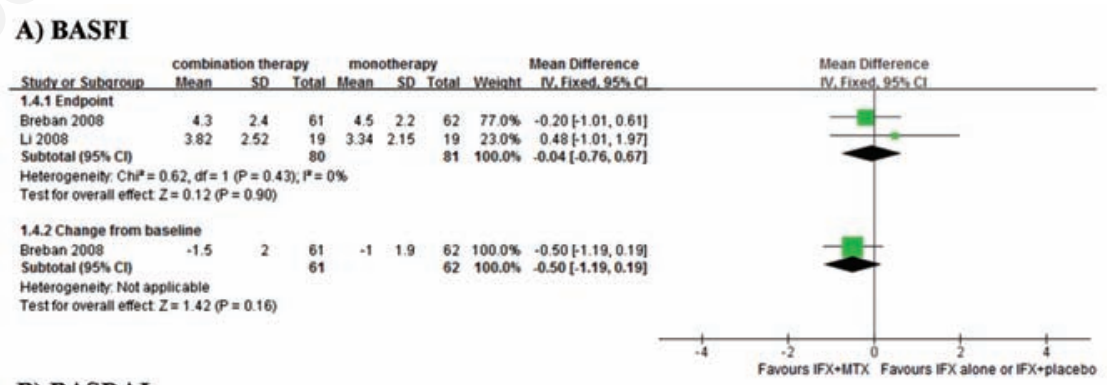

\section{B) BASDAI}

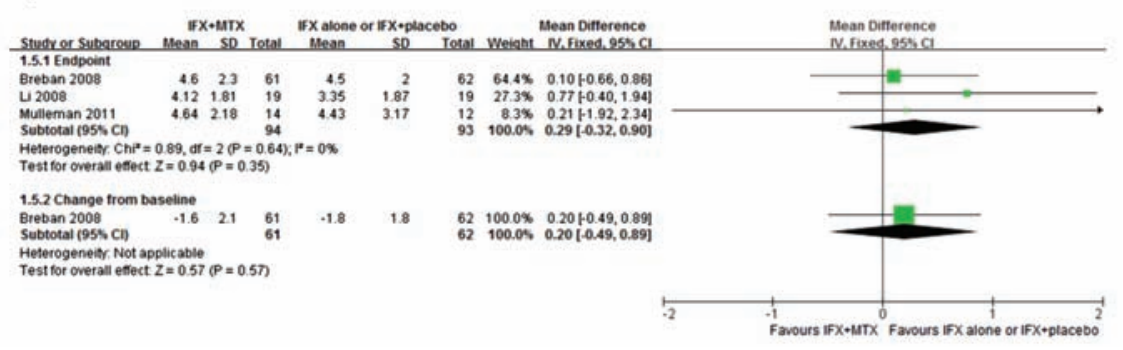

Figure 3. Forest plots of the Bath index of combination therapy versus monotherapy in ankylosing spondylitis. IFX, infliximab; MTX, methotrexate; BASDAI, Bath Ankylosing Spondylitis Disease Activity Index; BASFI, Bath Ankylosing Spondylitis Functional Index; CI, Confidence Interval; IV, Inverse Variance. 
heterogeneity was found between these two trials. WMD of endpoint value was 1.19 and 95\% CI -6.17 to 8.56 . This means combination therapy was similar with monotherapy in controlling pain.

Spinal mobility outcomes were reported in Breban 2008 trial, ${ }^{26}$ including chest expansion, Schober's test, occiput-to-wall test and fingersto-floor test. No significant difference was found in all these parameters. For patient global assessment (VAS 0-100), Breban 2008 trial reported both endpoint and change from baseline data and Li 2008 trial reported only the endpoint data. ${ }^{26,27}$ In our analysis, no significant difference was found in either individual or pooled results. WMD was - 1.08 and $95 \% \mathrm{CI}$ 7.98 to 5.81 .

For level of acute phase reactants outcomes, two trials assessed CRP (mg/L). ${ }^{26,27}$ The pooled result showed no significant difference. ESR (mm/hr) was assessed only in Breban 2008 trial, ${ }^{26}$ and no significant difference was found between the intervention groups.

Breban 2008 trial reported both endpoint and change from baseline data of the Medical Outcomes Study 36-Item Short-Form Health Survey (SF-36), ${ }^{26}$ which consisted of physical and mental components. MD of physical component were 0.60 (95\% CI -2.82 to 4.02) and 0.10 (-2.98 to 2.78) for endpoint and change from baseline, respectively. MD of mental component were -1.00 (95\% CI -4.91 to 2.91 ) and 1.90 (-5.23 to 1.43), respectively. Spinal inflammation was scored as the average of two VAS questions regarding the duration and intensity of morning stiffness in Li 2008 trial. ${ }^{27} \mathrm{MD}$ was 0.84 and $95 \%$ CI -0.54 to 2.22 . No significant difference was found in these outcomes.

\section{Sensitivity analysis}

Although the blinding was considered as high risk of bias, we did not perform sensitivity against allocation concealment and blinding as planned, because no positive result was found in all the assessed outcomes.

\section{Discussion}

\section{Summary of main results}

In this systematic review, we analyzed evidence from three RCTs comparing combination of TNF- $\alpha$ inhibitor and MTX with TNF- $\alpha$ inhibitor monotherapy for patients with AS. All three trials studied IFX and MTX combination. No RCT of other TNF- $\alpha$ inhibitor and MTX combination was found. The participants in the included trials were 187 adult AS patients who fulfilled modified New York criteria. ${ }^{17}$ The disease duration ranged from 4.5 to 12.1 years. Only one study was placebo controlled, and all of them examined small samples. ITT analysis was used for all major outcomes. Analysis of either individual trial data or pooled data found no significant difference between the intervention groups in all efficacy outcomes, including major and minor ones between combination therapy and monotherapy group. No significant heterogeneity was found among the trials. Neither statistically significant difference in withdrawals for side effects or for any reason was found between intervention groups.

\section{Quality and applicability of evidence}

The overall risk of bias was low in these three trials. In particular, only one study was placebo controlled. Therefore, performance bias and outcome assessment bias were

\section{(A) Withdrawal for side effect}

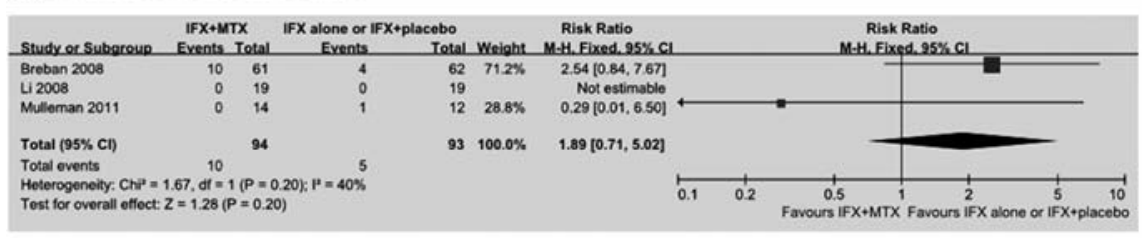

(B) Drop-out for any reason

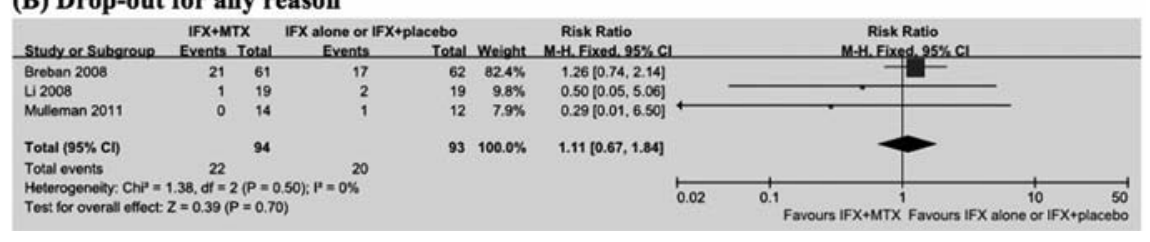

Figure 4. Forest plots of the safety outcomes of combination therapy versus monotherapy in ankylosing spondylitis. IFX, infliximab; MTX, methotrexate; CI, Confidence Interval; M-H, Mantel-Haenszel.

inevitable. Sample is another consideration. Some positive effect, especially those on peripheral arthritis, could be missed because the sample size was less than 200 in all the outcomes.

According to the result mentioned above, combination of IFX and MTX is not superior to IFX monotherapy. We found that the quality of evidence for combination regimen was Moderate. Moreover, the studies reported adequate methods of randomize, allocate, and outcome reporting, with consistent estimates for most outcomes. No significant heterogeneity was found in all outcomes. Considering the overall low risk of bias in and consistent result of the included trials, we believed this evidence is reliable although the sample size was not large enough. The small sample sizes, the short follow up and lack of other anti-TNF agents which may reduced the quality of evidence though this is considered unlikely. of course the evidence should not be applied to other TNF- $\alpha$ inhibitors (e.g. etanercept, adalimumab, golimumab and certolizumab) and MTX combination as well as juvenile SpA patients and those SpA patients who do not meet modified New York criteria, because they have not been tested so far.

\section{Comparison with other studies or reviews}

We have noticed that there was sound evidence showing the IFX and MTX combination was superior to IFX monotherapy in RA..$^{13,14}$ It might not be the case in AS. An open label, prospective study found that infliximab (IFX) in combination with MTX seemed to increase the efficacy of the therapeutic response in active AS patients. ${ }^{19}$ Glintborg et al. ${ }^{29}$ conducted a retrospective analysis of data of $842 \mathrm{AS}$ patients who received with a TNF $\alpha$ inhibitor as the first treatment, including disease activity, clinical response, treatment duration and predictors of drug survival (i.e. number of days individual patients maintained treatment). None of these parameters were found advantageous among those who received MTX in addition to TNF- $\alpha$ inhibitor. We have conducted another systematic review comparing MTX with no MTX in AS and did not find any benefit, which was quite different from that in RA. ${ }^{30,31}$ Perhaps the present review would further prove that MTX offer no benefit to AS patients, whether or not combined with TNF- $\alpha$ inhibitor. It is in consonance with ASAS/ EULAR recommendations on AS management. ${ }^{4}$

\section{Conclusions}

\section{Implications for practice}

Compared with TNF- $\alpha$ inhibitor monothera- 
py, TNF- $\alpha$ inhibitor combined with MTX did not increase response rate and offer benefit in pain, disease activity, MRI activity score, physical function, spinal mobility.

\section{Implications for research}

High quality of RCTs are needed to verify the benenfit and harm of TNF- $\alpha$ inhibitor and MTX combination for AS patients, especially for those with early phase.

\section{References}

1. Arends S, van der Veer E, Kallenberg CG, et al. Baseline predictors of response to TNF-alpha blocking therapy in ankylosing spondylitis. Curr Opin Rheumatol 2012;24:20998.2012;24:209-98.

2. Davis JC, van der Heijde D, Dougados M, et al. Reductions in health-related quality of life in patients with ankylosing spondylitis and improvements with etanercept therapy. Arthritis Rheum 2005;53: 494-501.

3. Zink A, Braun J, Listing J, et al. Disability and handicapin rheumatoid arthritis and ankylosing spondylitis: results from the German rheumatological database. German Collaborative Arthritis Centers. J Rheumatol 2000;27:613-22.

4. Braun J, van den Berg R, Baraliakos X, et al. 2010 update of the ASAS/EULAR recommendations for the management of ankylosing spondylitis. Ann Rheum Dis 2011;70:896-904.

5. Braun J, Brandt J, Listing J, et al. Treatment of active ankylosing spondylitis with infliximab, a double-blind placebo controlled multicenter trial. Lancet 2002;359:1187.

6. Van Den Bosch F, Kruithof E, Baeten D, et al. Randomized double-blind comparison of chimeric monoclonal antibody to tumor necrosis factor alpha (infliximab) versuss placebo in active spondylarthropathy. Arthritis Rheum 2002;46:755-65.

7. Gorman JD, Sack KE, Davis JC. Treatment of ankylosing spondylitis by inhibition of tumor necrosis factor alpha. N Engl J Med 2002;346:1349-56.

8. Davis JC Jr, Van Der Heijde D, Braun J, et al. Recombinant human tumour necrosis factor receptor, (etanercept) for treating ankylosing spondylitis-a randomized, controlled trial. Arthritis Rheum 2003;48: 3230-6.

9. Brandt J, Khariouzov A, Listing J, et al. Sixmonth results of a double-blind, placebo- controlled trial of etanercept treatment in patients with active ankylosing spondylitis. Arthritis Rheum 2003;48N6: 1667-75.

10. van der Heijde D, Dijkmans B, Geusens $P$, et al. Efficacy and safety of infliximab in patients with ankylosing spondylitis: results of a randomized, placebo-controlled trial (ASSERT). Arthritis Rheum 2005;52N2:582-91.

11. van der Heijde D, Kivitz A, Schiff MH, et al. Efficacy and safety of adalimumab in patients with ankylosing spondylitis: results of a multicenter, randomized, double-blind, placebocontrolled trial. Arthritis Rheum 2006;54N7:2136-46.

12. Inman RD, Davis JC Jr, Heijde DV, et al. Efficacy and safety of golimumab in patients with ankylosing spondylitis: results of a randomized, double-blind, placebo-controlled, phase III trial. Arthritis Rheum 2008;58N11:3402-12.

13. Maini RN, Breedveld FC, Kalden JR, et al. Therapeutic efficacy of multiple intravenous infusions of anti-tumor necrosis factor monoclonal antibody combined with low-dose weekly methotrexate in rheumatoid arthritis. Arthritis Rheum 1998;41: 1552-63.

14. Klareskog L, van der Heijde D, de Jager JP, et al. Therapuetic effect of the combination of etanercept and methotrexate compared with each treatment alone in patients with rheumatoid arthritis: double-blind randomised controlled trial. Lancet 2004;363:67581.

15. Kuriya B, Arkema EV, Bykerk VP, et al. Efficacy of initial methotrexate monotherapy versus combination therapy with a biological agent in early rheumatoid arthritis: a meta-analysis of clinical and radiographic remission. Ann Rheum Dis 2010;69: 1298-304.

16. Haibel H, Sieper J. Use of methotrexate in patients with ankylosing spondylitis. Clin Exp Rheumatol 2010;28:S128-131.

17. Olivieri I, van Tubergen A, Salvarani C, et al. Seronegative spondyloarthritides. Best Pract Res Clin Rheumatol 2002;16:723-39.

18. Higgins J, Green S. Cochrane handbook for systematic reviews of intervention. Ver. 5.1.0. 2011. Available from: http//www. cochrane. org Accessed: January, 2013.

19. Pérez-Guijo VC, Cravo AR, Castro Mdel C, et al. Increased efficacy of infliximab associated with methotrexate in ankylosing spondylitis. Joint Bone Spine 2007;74:254-8.

20. Krzysiek R, Breban M, Ravaud P, et al. Circulating concentration of infliximab and response to treatment in ankylosing spondylitis: results from a randomized control study. Arthritis Care Res 2009; 61:569-76.

21. Ternant D, Mulleman D, Lauféron F, et al.
Influence of methotrexate on infliximab pharmacokinetics and pharmacodynamics in ankylosing spondylitis. Br J Clin Pharmacol 2012;73:55-65.

22. Ducourau E, Ternant D, Lauferon F, et al. Methotrexate does not influence infliximab pharmacokinetics and concentration-effect relationship in ankylosing spondylitis. Arthritis Rheum 2010;62:1945.

23. NCT1. Infliximab and methotrexate in ankylosing spondylitis. NCT00507403. 2009. Available from: www.clinicaltrials. gov. Accessed on: January, 2013.

24. NCT2. Study of two schedules of infliximab maintenance therapy in ankylosing spondylitis. NCT00439283. 2004 Available from: www.clinicaltrials.gov. Accessed on: January, 2013.

25. NCT3. Combination methotrexate and infliximab. NCT00432432. 2006. Available from: www.clinicaltrials.gov. Accessed on: January, 2013.

26. Breban M, Ravaud P, Claudepierre P, et al. Maintenance of infliximab treatment in ankylosing spondylitis: results of a one-year randomized controlled trial comparing systematic versus on-demand treatment. Arthritis Rheum 2008;58:88-97.

27. Li EK, Griffith JF, Lee VW, et al. Short-term efficacy of combination methotrexate and infliximab in patients with ankylosing spondylitis: a clinical and magnetic resonance imaging correlation. Rheumatology (Oxford) 2008;47:1358-63.

28. Mulleman D, Lauféron F, Wendling D, et al. Infliximab in ankylosing spondylitis: alone or in combination with methotrexate? A pharmacokinetic comparative study. Arthritis Res Ther 2011;13:R82.

29. Glintborg B, Ostergaard M, Krogh NS, et al. Predictors of treatment response and drug continuation in 842 patients with ankylosing spondylitis treated with anti-tumour necrosis factor: results from 8 years' surveillance in the Danish nationwide DANBIO registry. Ann Rheum Dis 2010;69:2002-8.

30. Suarez-Almazor ME, Belseck E, Shea B, et al. Methotrexate for treating rheumatoid arthritis. Cochrane Database Syst Rev 2003; CD000957.

31. Katchamart W, Trudeau J, Phumethum V, et al. Methotrexate monotherapy versus methotrexate combination therapy with nonbiologic disease modifying anti-rheumatic drugs for rheumatoid arthritis. Cochrane Database Syst Rev 2010;CD008495. 